“(C) 2015 IEEE. Personal use of this material is permitted. Permission from IEEE must be obtained for all other uses, in any current or future media, including reprinting/republishing this material for advertising or promotional purposes, creating new collective works, for resale or redistribution to servers or lists, or reuse of any copyrighted component of this work in other works." 


\section{Storage for renewable energy}

\section{applications in the Australian context}

By Anthony Vassallo, Phil Maker, Tim Dixon \& Vassilios Agelidis

\section{Introduction}

Exploiting renewable energy sources makes sense on many levels. Firstly as a response to the world's reliance on fossil fuels, in order to reduce climate changing emissions. But beyond that, more mature renewable generation technologies deployed in areas naturally blessed with abundant renewable resources are beginning to challenge traditional fuels for cost-effectiveness, even as subsidies for low carbon generation are wound back.

However, the natural variability of some renewable sources such as wind and solar creates substantial challenges for conventional electricity grids that have evolved to a dispatch type platform, where a variable load is met through five minute dispatch of controllable generation. As a greater proportion of generation is provided by renewables, the ability to dispatch generation at will becomes increasingly difficult. The problem very simply becomes one of trying to meet a variable load with variable supply. It is here that energy storage promises to significantly increase the stable, reliable penetration of renewables into the grid, and perhaps in the long term, make grid disconnection a viable alternative for many users. 


\section{Household storage trends and applications}

This section briefly looks at some of the drivers for small-scale storage in Australia, including the current trends towards higher electricity prices and increased penetration of household solar photovoltaic (PV) generation.

\section{Background - current and near term status of small-scale renewable generation}

The last decade has seen a dramatic rise in retail electricity prices in Australia coinciding with markedly reduced industrial and residential demand for grid-supplied power.

Figure 1 - PV system cost per kW since 2010, Australia, by installation size

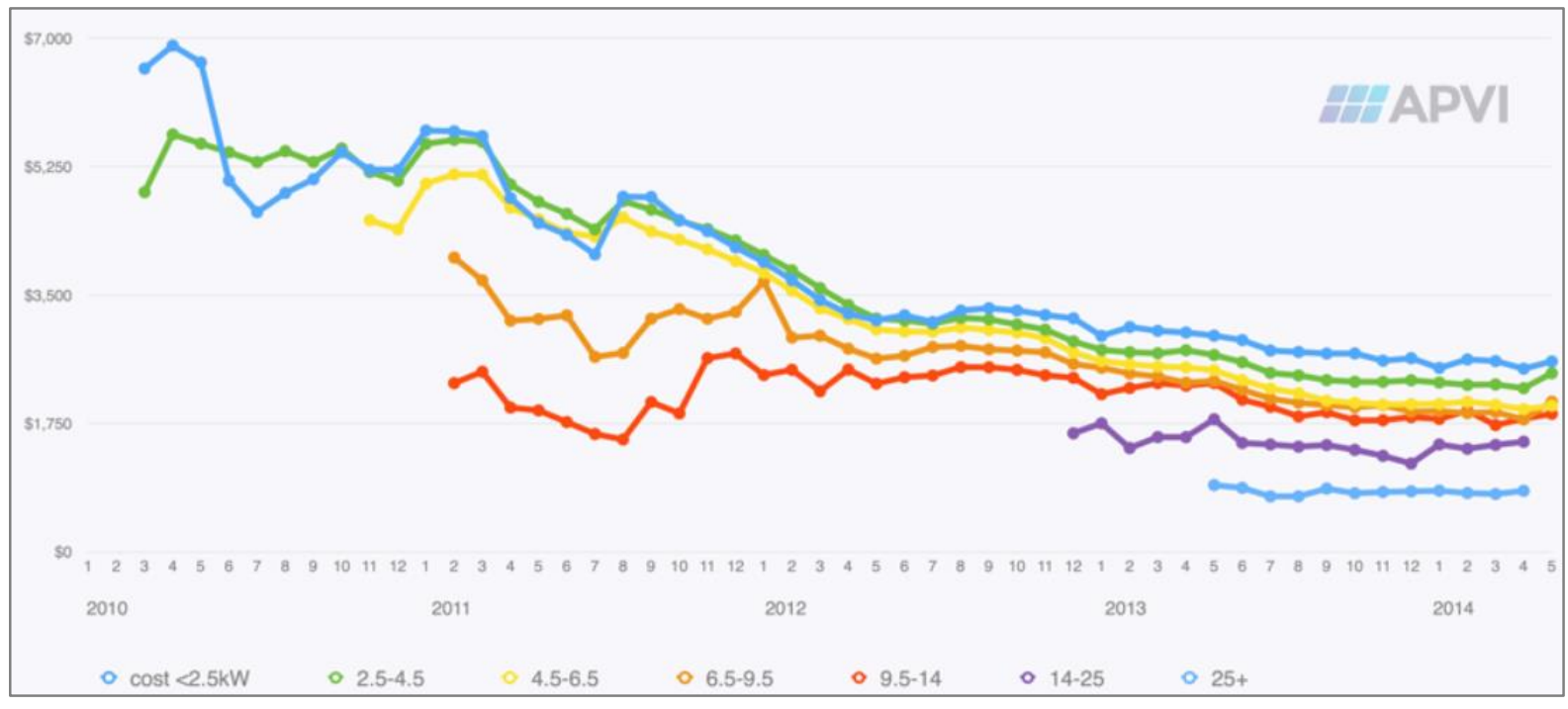

Since May 2004, the average Australian retail price of electricity has more than doubled, mainly driven by increases in network tariffs. At the same time, declines in electricity demand have been accelerating; The Australian Energy Market Operator estimates that overall National Electricity Market (NEM) demand fell from a peak of 198TWh in 2009/10 to 184 TWh in 2013/14 - well below the demand levels seen a decade ago.

This decline in demand has been fuelled by the loss of some energy intensive industries from Australia, as well as increased take up of energy efficiency measures by households and businesses, and - significantly - a rapid increase in the installation of household rooftop solar PV generation. 
This has been aided by a dramatic decrease in the price of PV in Australia over the last few years.

System costs have fallen from between AUD $\$ 5,000$ to AUD $\$ 7,000$ per $\mathrm{kW}$ in 2010 , to around AUD $\$ 3,000$ per $\mathrm{kW}$ as of 2015 (see Figure 1 above).

Figure 2 below shows the correlation between rising electricity prices and an increase in Australian PV output. In the graph, PV output has been shifted back six months to account for the estimated lag between a price rise and the time taken for that to result in a decision to install a PV system.

Figure 2 - Average Australian retail electricity price index (base = Mar 2005) (LHS) and Australian PV output (MW) (RHS)

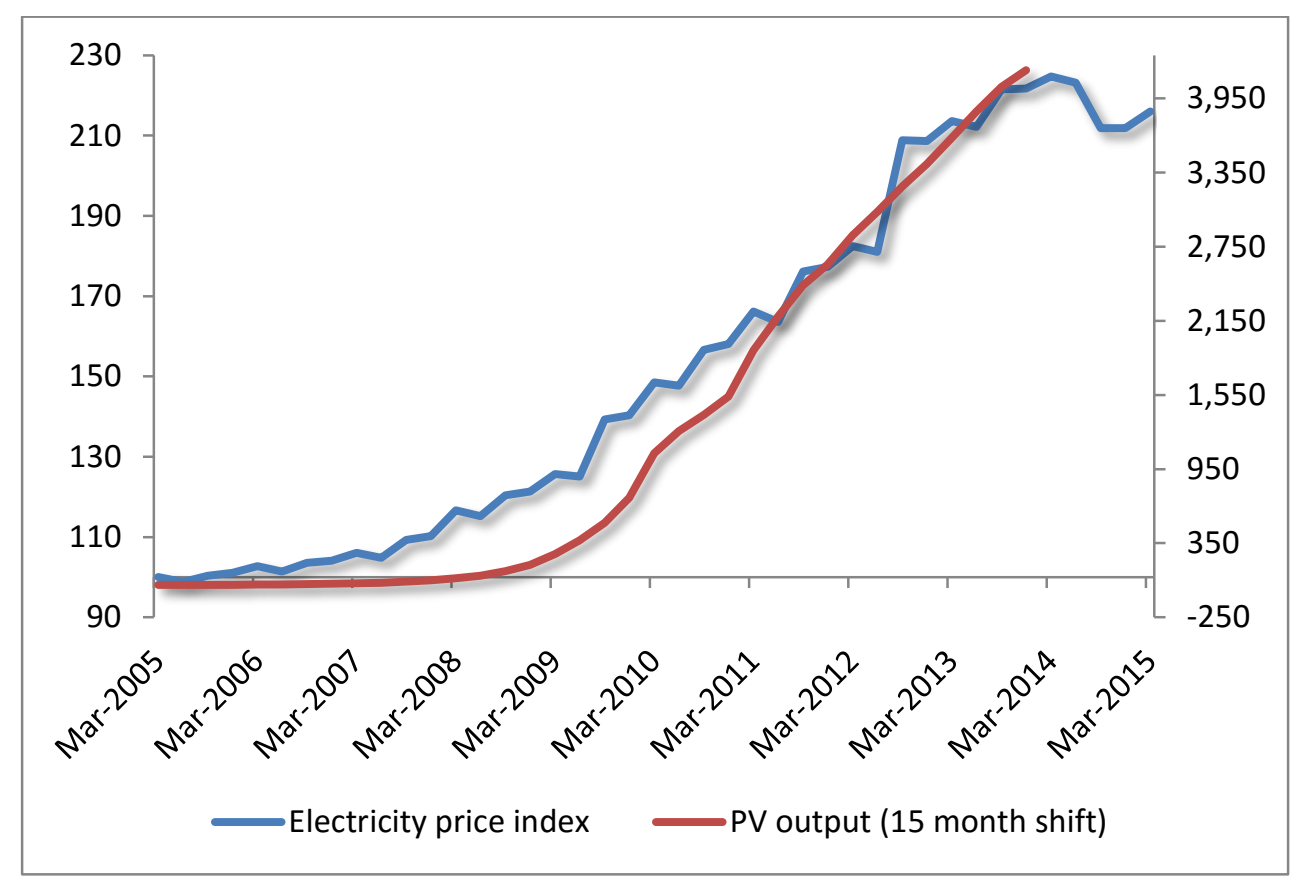

These two trends have combined to create a scenario commonly termed by those in the industry as the "death spiral"; as more Australians install rooftop solar, they contribute to further reducing demand for grid-supplied electricity, meaning fixed network costs drive up the average electricity price - which in turn compels more households to install PV to reduce their demand from the grid. However, this so-called "death spiral" may finally evolve into the "coup de grâce" of the traditional utility business model, with the widespread adoption of small-scale storage to complement PV. 
Analysis of effects of this distributed generation: non coincidence of output and load, especially for homes, suggesting storage as a way to optimise

Despite the recent steep rises in electricity prices partly contributing to greater installation of PV systems, most users have remained firmly connected to the grid. The fact that solar generation and typical load curves do not match have meant that, although overall household consumption has fallen, most people continue to rely on grid-supplied power for much of their total energy, and all of it after dark.

PV output is strongest when household demand is low (see Figure 3 below), meaning there is excess energy produced during the shoulder consumption period, while power cannot be directly supplied by the solar system during much of the peak period. What is more, solar energy used by the premises at these peak times is many times more valuable than if it is exported back to the grid.

Figure 3 - Typical household consumption and PV generation profile, $c / k W h$ by hour of day

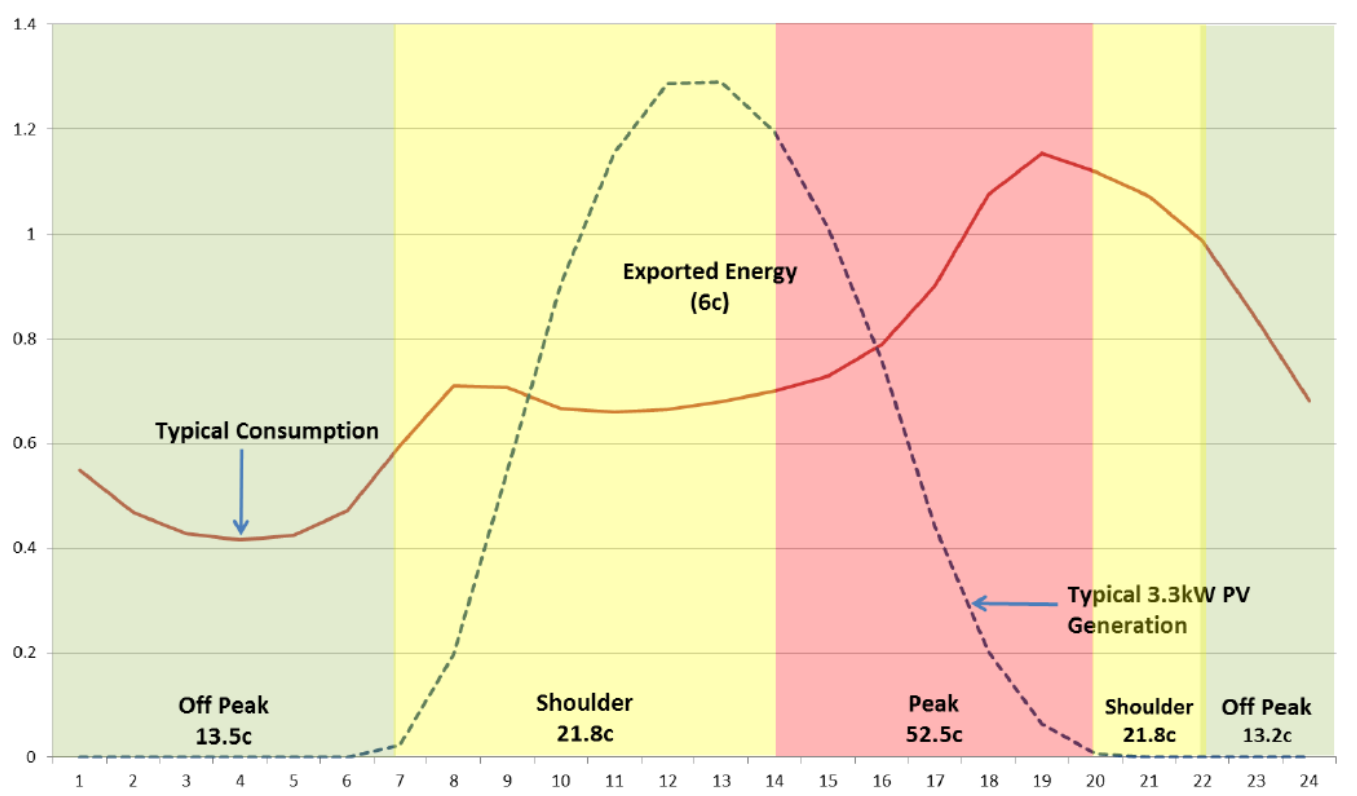

Currently electricity generated by rooftop PV is fed back into the grid at $6 \mathrm{c} / \mathrm{kWh}$, while peak power consumed by the household is worth $52.5 \mathrm{c} / \mathrm{kWh}$ - a difference of $46.5 \mathrm{c} / \mathrm{kWh}$. As prices in the NEM for excess solar energy have fallen sharply, the economic case for storage has been further 
strengthened. This is especially the case if battery energy storage system (BESS) costs continue to fall as forecast.

Apart from daily variations in generation, solar PV (and wind energy) is subject to rapid variations in frequency and voltage output, depending on natural weather conditions which change constantly, and often extremely quickly. For example, wind speed in some areas can go from $15 \mathrm{~m} / \mathrm{s}$ to $0 \mathrm{~m} / \mathrm{s}$ within just a few seconds.

This short-term intermittency can be offset by strategies including plugging into non-renewable sources when required, controlling load by turning off certain devices at specified times or situations, and controlling various generation sources with different responses when available. However, one of the most effective solutions is to deploy storage to address this problem.

\section{Types, use and optimisation of storage in residential applications}

Types and use

Most residential storage systems are now lithium-based chemical batteries, with a multitude of suppliers from the US, China, Korea, Japan and Europe offering multiple off-the-shelf products. The typical capacity of these batteries is between $5-15 \mathrm{kWh}$. These systems typically include a hybrid gridtied inverter (2-5 kW) and solar PV MPPT controller and battery charger.

In Australian residential areas, the average daily household consumption is $19 \mathrm{kWh}$, so these systems can only store between $25-80 \%$ of the average daily energy required.

However, as discussed above, one of the most valuable roles for storage is to reduce or eliminate the need for grid-sourced energy in the peak period. So depending on the individual household load profile, the available energy from these batteries may be sufficient to satisfy the load during this period, which is typically from $14: 00$ to $20: 00$. 
Currently, most household storage is operated within a simple schedule designed to charge the BESS from the grid during off-peak hours, and to provide the load with either PV or combined PV and storage during the day. Excess PV, if available, can be exported (providing the local utility allows) but only after the battery is fully charged. During the evening and night, the BESS is discharged to reduce or eliminate any import during peak tariff periods.

\section{Optimisation}

There is a great deal of scope to optimise household electricity usage and generation via the combination of PVs, storage, demand management and grid supply. Essentially the addition of storage into the mix allows intelligent load and generation shifting, so that a homeowner can reduce their electricity bills by minimising their peak and shoulder period consumption.

However, to more fully utilise the storage resource, it is necessary to anticipate the next day's PV output and expected load. This is important because the battery state-of-charge (SoC) must be in the correct band for the daily requirement. For example, if the upcoming day is likely to be overcast but the load high, then the battery should be almost fully charged during the off-peak period. Conversely, if the PV output is expected to be high, but with a modest load, then the battery can start the day with a very low state of charge, since the morning PV can be used to charge the BESS in preparation for the late afternoon peak period. This necessitates accurate load and PV forecasting, and an optimisation routine to provide the optimum morning battery SoC.

There has been much discussion and speculation on the feasibility of widespread household grid independence through a combination of PV and storage. While this is technically feasible, our analysis indicates that for many Australian households it would be a very expensive exercise to achieve both grid independence, and grid-equivalent levels of reliability (refer to Khalilpour and Vassallo in further reading). This results from the need to provide sufficient storage to meet those periods where high load with low PV generation coincide. 
To approach $97 \%$ reliability (that is, to not meet the load for 260 hours per year), as much as $50 \mathrm{kWh}$ of storage combined with $10 \mathrm{~kW}$ of PV is required. Given that most available systems have a capacity of between $5-15 \mathrm{kWh}$, that means anywhere from three to 10 systems with typical characteristics would need to be installed in every household that wanted to achieve grid independence.

Figure 4-Optimisation and control schematic for renewable energy systems

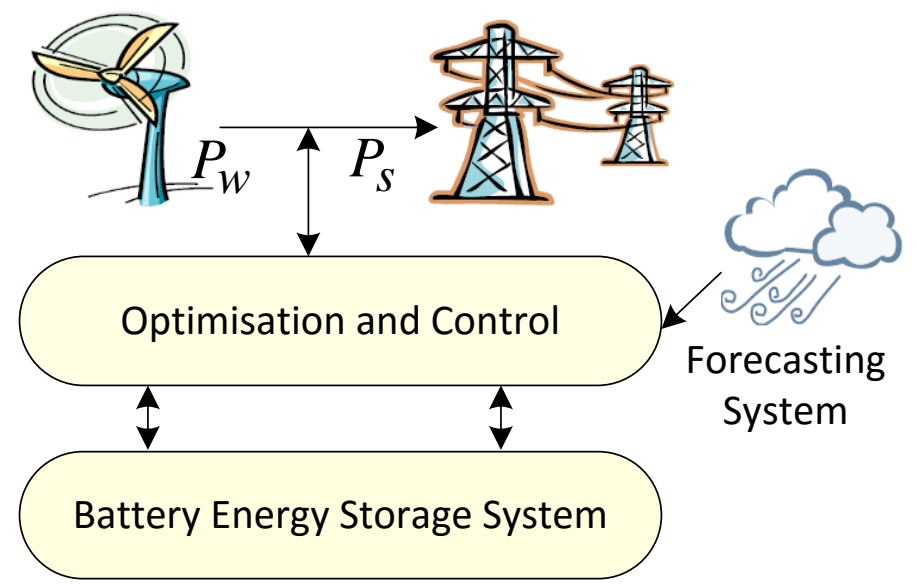

Of course many homes will not require this much storage or as much PV, but this example demonstrates the challenge of providing grid-level reliability solely with local generation and storage. Our analysis also shows that by keeping the grid connection, extra value can be captured through PV export, especially as PV systems become less expensive, and more capacity is installed.

Apart from the benefits that storage can provide to the homeowner, there is also an opportunity for distribution network service providers to call on distributed storage in their network to manage peaks, voltage issues and load growth. This would require an agreement between the homeowner and the utility, or operate through an intermediary third party that provided an aggregation of home energy storage systems to the utility (the New Zealand network operator Vector has already established a model based on these principles).

\section{Potential impact of electric vehicles as mobile storage}


One possible disruptor to the current scenario is the future proliferation of electric vehicles (EVs).

The latest generation of EVs, such as the Tesla model S, have ranges in excess of $500 \mathrm{~km}$ per charge, with subsequent models likely to push that figure out even further. Thinking about this in purely electrical terms, the storage capacity of next-gen EVs is actually many times that of typical household BESS commonly available.

As discussed above, average Australian household consumption is typically 19kWh per day, which would require about $50 \mathrm{kWh}$ of storage supplementing $10 \mathrm{~kW}$ of PV to provide grid-level reliability. The current generation Tesla S has a storage capacity of $85 \mathrm{kWh}$, and there is the potential for some of this capacity to be used to power households.

Figure 5 - The Tesla S electric vehicle has a storage capacity of $85 \mathrm{kWh}$

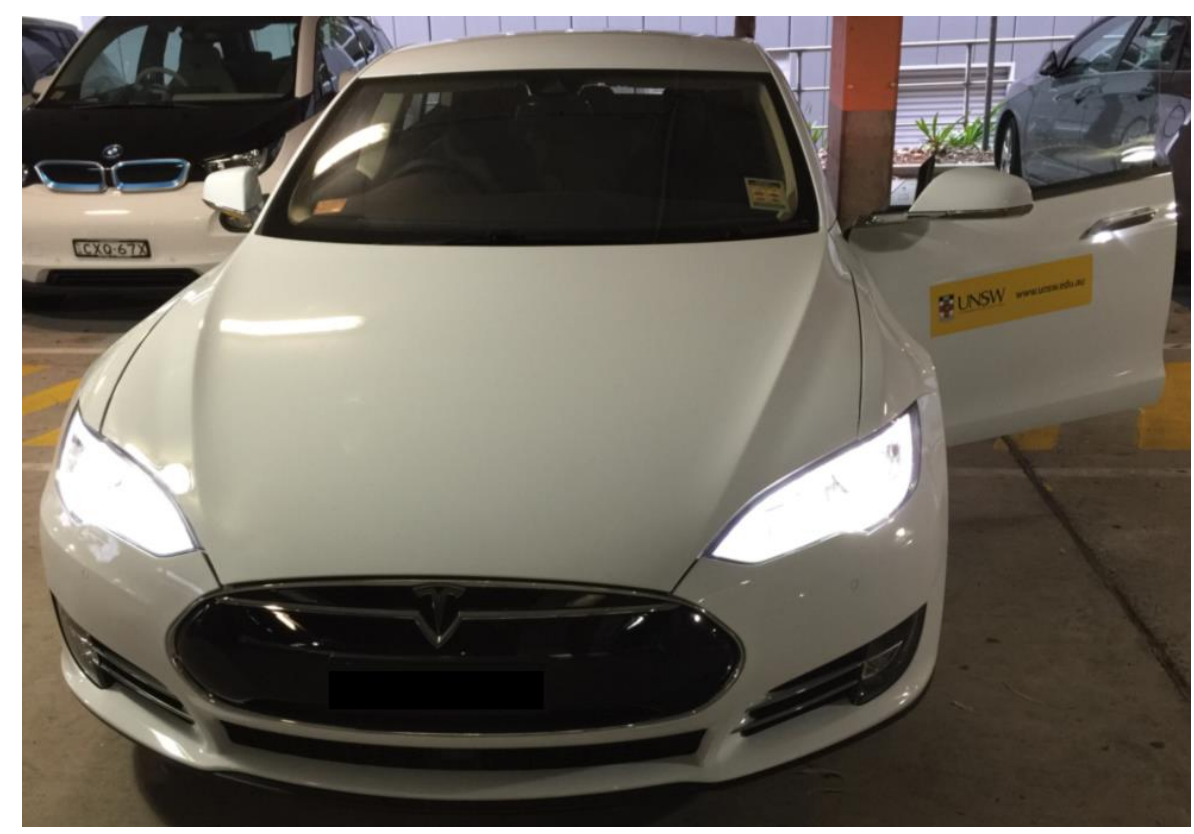

The maximum range of next-gen EVs is more than adequate for average commuting distances in urban areas, meaning only a fraction of the total storage capacity is likely to be used on a typical day. This means that drivers may elect to use some of their EV's storage capacity to power their homes during evening peak times, which is typically just after they arrive home from work. The EV could then either charge overnight from the grid during the non-peak period, or drivers may seek to charge their vehicles from PV while they are at work during the day. 
While such charging infrastructure is not yet available, it is highly likely that, as the level of EV ownership increases to a critical mass, associated infrastructure and services such as fast charging stations and charging of EVs in secure car parking (possibly utilising renewable generation) will follow the growing EV market.

As with traditional fixed household storage systems, there is a need to accurately predict likely PV output and EV usage for the following day in order to ensure the optimal SOC for the EV battery based on its expected future use. This becomes less critical, however, if there are two or more EVs in the household, bearing in mind that many households currently have a second internal combustion engine (ICE) car. The ability to draw power from two or more EVs makes the system more complicated but correspondingly allows greater scope for optimisation.

Finally, there are possible lifecycle benefits to EVs which could further impact the distributed storage potential of the technology. As car owners upgrade their vehicles periodically, there may be an economic incentive to extract the storage from older model EVs to install as fixed household storage, as the capacity gained may be worth more than the resale value of a used EV. Bearing in mind depreciation in value of ICE cars can amount to the majority of the original purchase price in just a few years, this effect is likely to be magnified in the context of EVs, as the technology in and specifications of these vehicles is developing at an even faster rate than other automotive products, meaning previous models become obsolete faster. It may be that the value to a household of a used EV on the second hand car market - even if a guaranteed buyback value is offered by the manufacturer - would be less than the value of utilising the embedded storage capacity in the context of a grid-independent PV/storage system.

\section{Large scale storage options for high voltage networks}

Having discussed storage issues at the distributed or household level, we will now look at the situation and potential for large or utility scale storage. 
There is a clear role for energy storage in the electricity transmission network, although the types of storage technologies and their operation are very different at the grid level compared to the household level.

Putting aside the use of storage for power quality issues (that is, at the second and subsecond time scales), storage needs to be at the hundreds of MWh scale if it is going to impact on typical high voltage loads. Conventionally, this level of storage has been provided by hydropower. However, the effectiveness of this technology is highly dependent on location and subject to the availability of water and suitable topography.

Other forms of large scale storage have been demonstrated overseas, such as underground compressed air energy storage (CAES), with two well-known plants in use in the Unites States. However this technology has not been trialled commercially in Australia. Like hydropower, CAES is somewhat dependent on topography, as large, airtight, underground tanks or naturally-occurring caverns are required in order to supply significant storage capacity.

The use of large, single battery energy storage systems for utility scale applications is technically feasible, but the financial viability is currently very low. However, the intelligent use of multiple storage systems in the 10-50 MWh range can be effectively used to reduce or eliminate network congestion, and may allow deferral of significant capital expenditure such as expensive line upgrades and augmentation. These smaller scale storage systems may be modular and of the same type, of different sizes and technologies, centrally located, or distributed throughout the network.

Regardless of the type and location of the storage assets utilised, it is important that they are used only when it is economically beneficial to do so. The average wholesale value of electricity can be an order of magnitude lower than peak retail tariffs, so securing sufficient revenue to cover the cost of storage assets can be challenging. 
However, intelligent dispatch of storage based on real time price signals can allow storage assets to dispatch energy only when the price in the National Electricity Market (NEM) is above the life-ofasset price of electricity generated by the asset. That is, the price received for electricity must be greater than the depreciation of averaged value, based on reduction in life of the asset incurred by a dispatch event.

\section{Applying hybrid energy storage solutions through intelligent control}

Just as electricity from storage must be dispatched only when market conditions make it profitable to do this, the type and characteristics of storage assets must be taken into account and matched to demand in order to prolong the life of those assets.

Figure 6-Hybrid energy storage research project at AERI, UNSW Australia

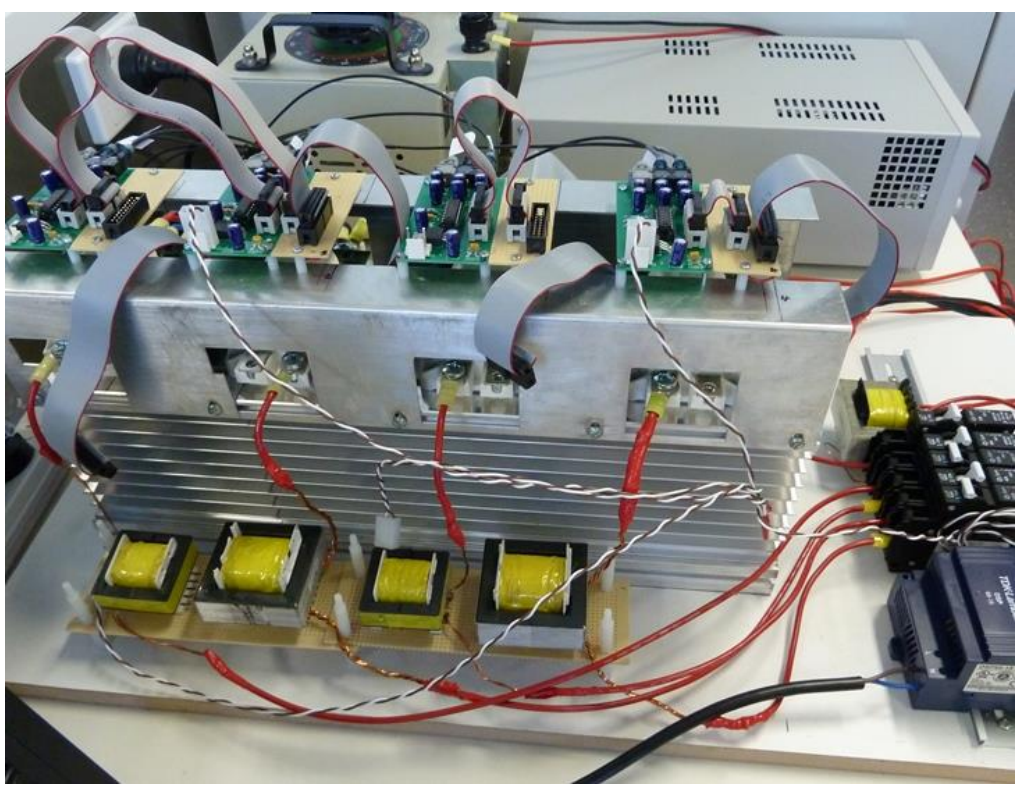

It is commonly accepted that there is no one generation technology suited to all applications, and so it is with storage technologies. For example, lithium ion (Li-ion) batteries are relatively cheap to produce and their characteristics are well-known and largely predictable given it is a mature technology. However, Li-ion performance is sensitive to temperature and repeated deep discharging can significantly reduce the number of cycles the battery can withstand, reducing overall life very quickly. Conversely supercapacitors are able to quickly and deeply charge and discharge without 
suffering the ill effects experienced by lithium-based batteries. On the downside, they are unable to provide a stable power supply over a long period. Flow batteries such as vanadium redox batteries (VRBs) have much lower power densities than Li-ion batteries but are more tolerant of heat as well as being able to completely charge/discharge without reducing the life of the battery.

Research and development efforts will address some of the shortcomings of individual technologies at the materials and design level, maximising performance and reducing production costs for individual types of storage technologies. However, in our view, the key is to maximise efficiency of the wider system by utilising the complementary strengths and weaknesses of various storage technologies, and by matching asset characteristics to load profiles.

Furthermore, if smaller storage assets are to be deployed throughout the network, much thought must be given to planning the location of each asset, and complementary technologies should be colocated to function independently in a hybrid system, which can respond more effectively to variable demand conditions. 
Figure 7-Topology of hybrid energy storage and control system in combination with a solar PV array

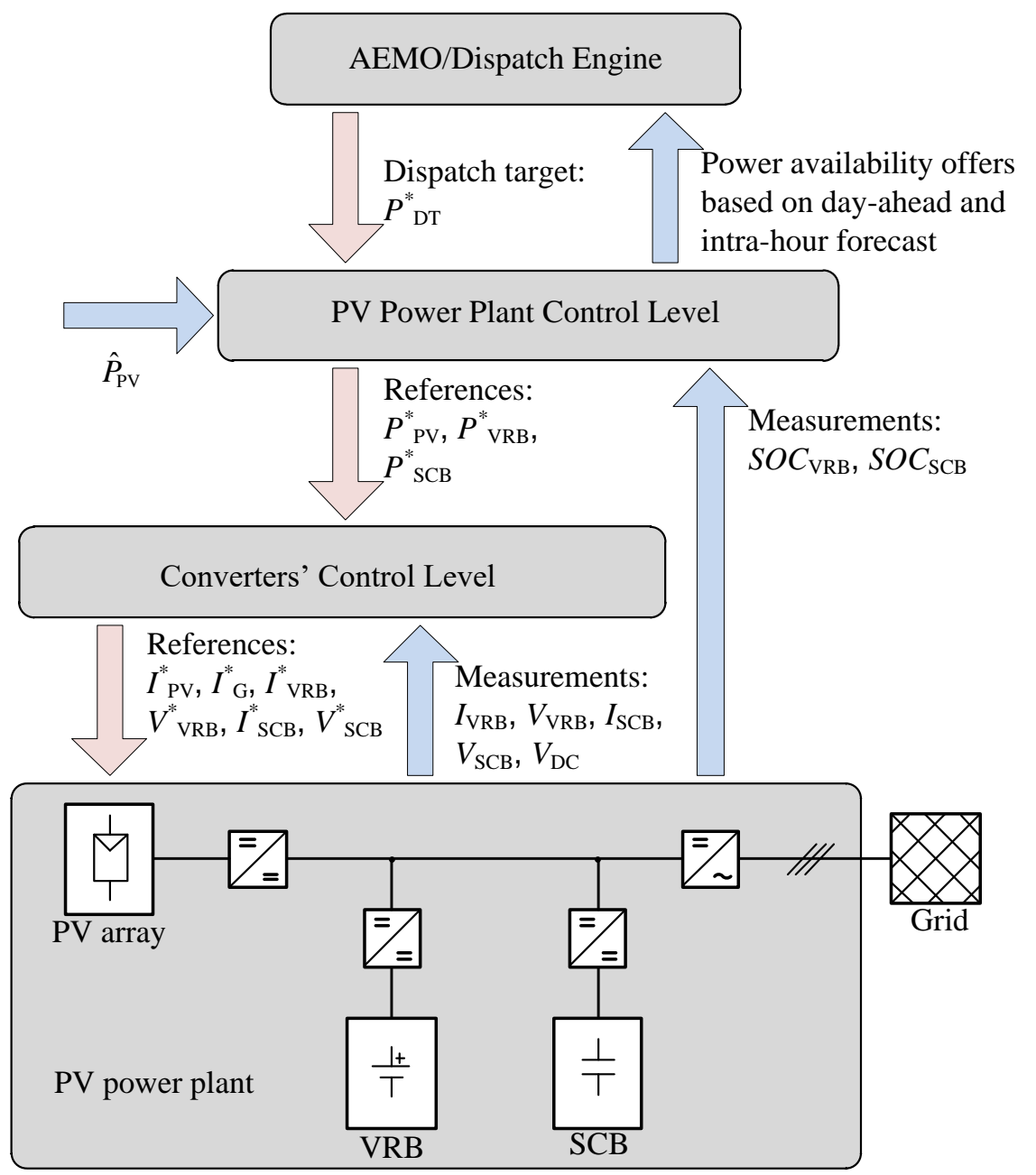

\section{High renewable penetration and storage in remote minigrid applications}

Total renewable energy penetration is still at relatively low levels in Australia, particularly along the urbanised east coast population centre. While South Australia has experienced peak renewable penetration of over $25 \%$, some microgrids in rural and remote areas are experiencing average renewable energy (mostly PV and wind) penetration of around $50 \%-60 \%$, with peak penetration approaching and in some instances reaching $100 \%$. Maintaining grid stability despite the high level of renewable penetration is made possible by intelligent deployment of storage. 
In these minigrid environments storage is primarily used for frequency and voltage stabilisation, and typically requires a combination of flywheel and/or BESS, high speed load control, and synchronous compensators in order to maintain grid stability.

Flywheels are particularly suited to rapidly counteracting the frequency and voltage variations associated with renewable energy, maintaining power quality in instances of high renewable penetration. Typically they are comprised of a bearing-supported rotor (the flywheel) suspended in a vacuum chamber. Electricity is stored in the form of kinetic energy used to spin the rotor, and this kinetic energy can be quickly converted back into electricity by slowing the spinning disc.

Case Study: King Island, Tasmania

King Island off the north-west cost of Tasmania sits in the middle of the 'roaring forties', and has a population of around 1,500 people. The island's minigrid is supplied by a combination of wind (two wind turbines producing 1,700kW), solar PV (total capacity of $390 \mathrm{~kW}$ ) and diesel/biodiesel generators.

Storage is principally supplied by a hybrid lead-acid/supercapacitor BESS supplying $3 \mathrm{MW}$ of power and storing 1.6 MWh of useable energy. In fact this was the largest battery ever installed in Australia at the time. Originally a VRB was installed as the preferred BESS technology, however due to an operational event the VRB was eventually decommissioned and replaced by the current lead acid BESS. Graphite heat block storage systems and flywheels also supplement the BESS, and together this has allowed stability at an average of $50 \%$ renewable energy penetration on the island, including instances of peak penetration reaching $100 \%$. 


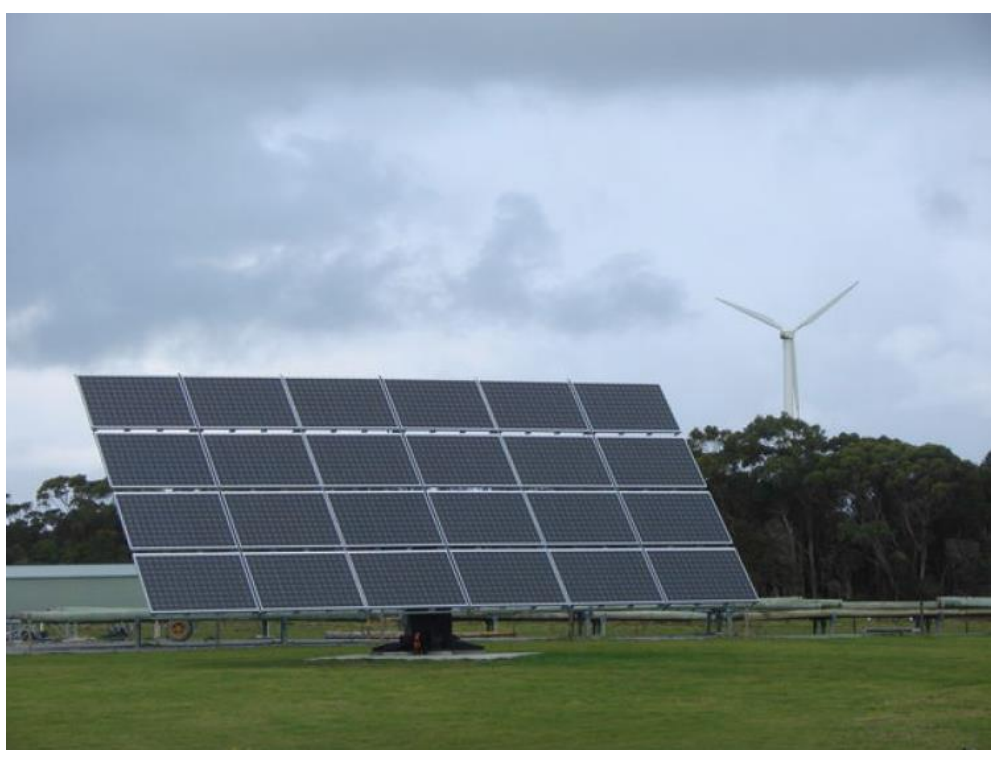

Case Study: Coral Bay, Western Australia

Coral Bay is a small community on the remote north-west coast of Western Australia, with a permanent population of around 150 people. The town's minigrid is supplied by three $225 \mathrm{~kW}$ wind turbines with a maximum output in strong gusts of up to $400 \mathrm{~kW}$. The output of the turbines varies as the frequency varies, and this provides additional management challenges.

Figure 9-PowerStore flywheel at Coral Bay, Western Australia

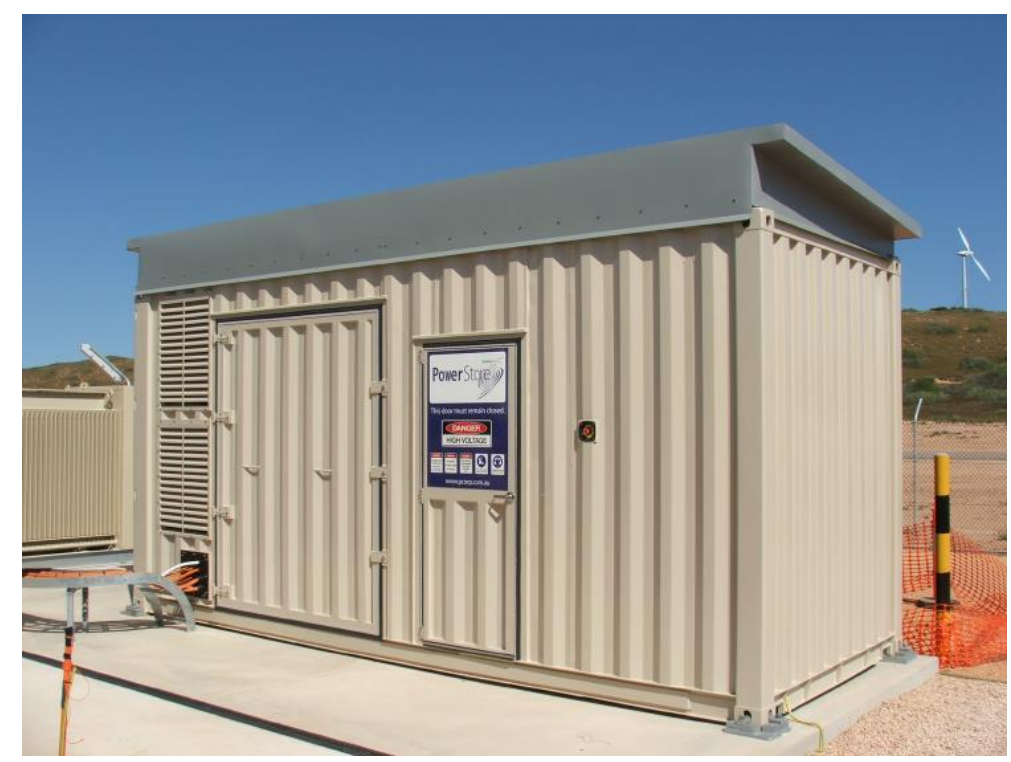


The wind turbines are supplemented by four $320 \mathrm{~kW}$ low load diesel generators running at $7 \%$, which can start and synchronise to the grid in around 10s with the aid of an 18MWs at +/-500kW flywheel storage unit which has been deployed to stabilise the grid (see figure 9 above).

This has resulted in stability at 93\% renewable energy penetration (see figure 10 below).

Figure 10 - Coral Bay performance: 93\% renewable penetration with stabilisation

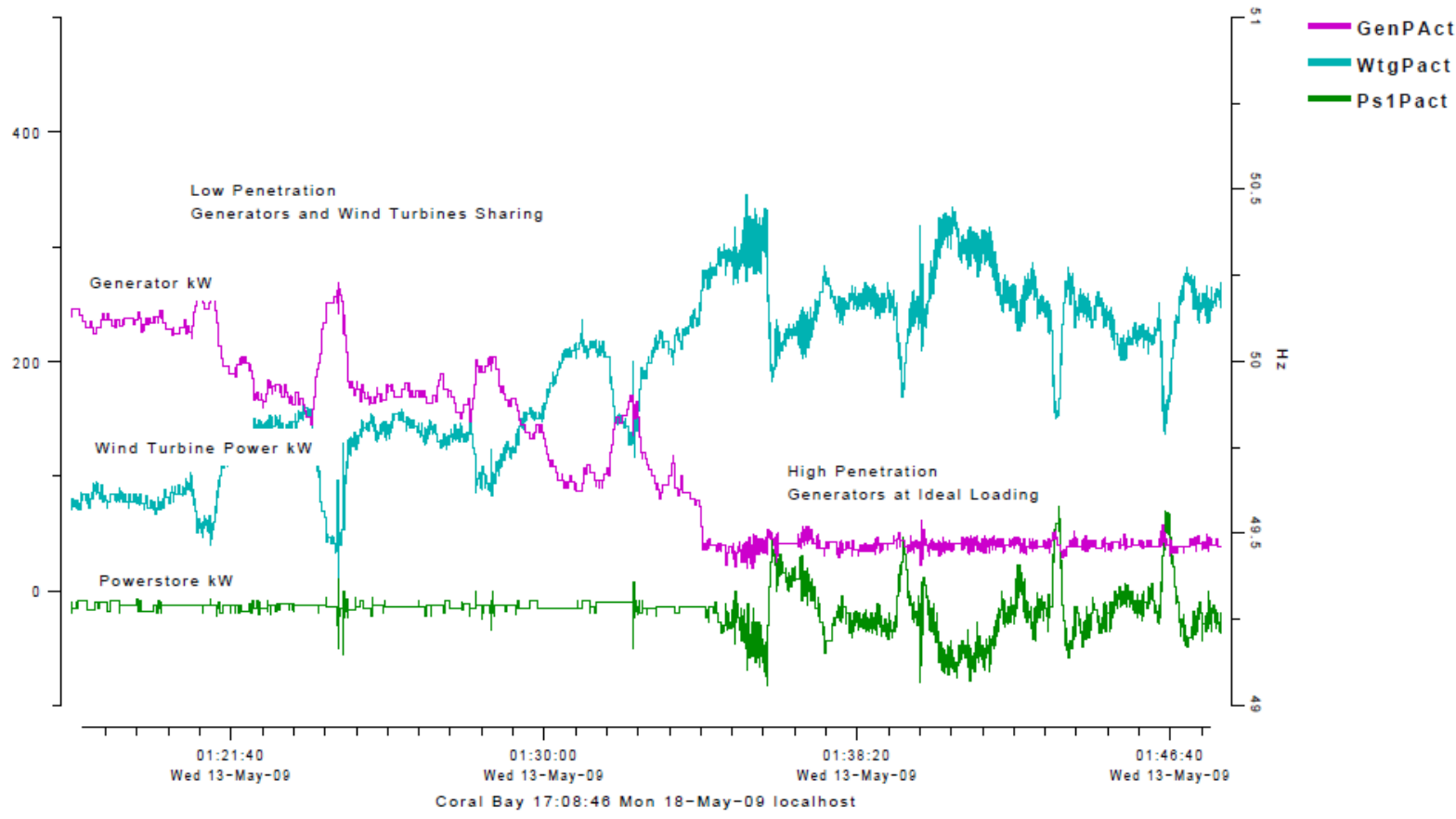

Successful management of very high renewable penetration minigrids can provide a blueprint for higher penetrations in the 'big grid'. However, it is a given that applying city-level power quality to remote communities is prohibitively expensive. Attempts to maintain power quality in larger grids will limit the ability to improve renewable penetration, without the proliferation of storage.

\section{Further reading}

Electricity Storage. [Online]. Available:

https://www.sbc.slb.com/SBCInstitute/Publications/ElectricityStorage.aspx

Australian PV installations since April 2001. [Online]. Available: http://pv-map.apvi.org.au/analyses 
R. Khalilpour and A. Vassallo, "Leaving the grid: An ambition or a real choice?" Energy Policy, vol. 82, pp. 207-221, July 2015

B. Hredzak, V.G Agelidis, G. Demetriades, "Application of explicit model predictive control to a hybrid battery-ultracapacitor power source", accepted for publication in Journal of Power Sources, 30 November 2014.

\section{Biographies}

Professor Anthony Vassallo holds the Delta Electricity Chair in Sustainable Energy Development at the University of Sydney, in the School of Chemical \& Biomolecular Engineering. He took up this position in October 2008. Prior to this, he held the position of Senior Principal Research Scientist with the Commonwealth Scientific \& Industrial Research Organisation, followed by a period of consultancy to industry and government in the field of sustainable energy technology. Tony has a $\mathrm{PhD}$ in Chemistry from Macquarie University. He is the immediate past President of the Australian Institute of Energy, and leader of the Clean Energy Research Cluster in the Faculty of Engineering at the University of Sydney.

Phil Maker is a Senior Control Engineer at Powercorp, based in Darwin, Australia. He has extensive experience in the field with high renewable penetration minigrids supplemented by energy storage. He has been involved with developing, testing, and commissioning a variety of systems including life critical systems.

Tim Dixon is with the Australian Energy Research Institute (AERI) at UNSW Australia, Sydney. He is responsible for the AERI's strategic planning and business development, and has previously held positions at the NSW Government, with a focus on strategic policy and international business activities. Tim has a Bachelor of Arts (Honours) from the University of Sydney, and is currently studying a Master of Commerce (International Business) at that institution. 
Professor Vassilios G. Agelidis is the Director of AERI and Professor of Power Engineering at the School of Electrical Engineering and Telecommunications at the UNSW. Professor Agelidis is one of Australia's leading authorities on efficient electricity grid technologies and power engineering. He has done extensive research in the field of 'smarter' grid infrastructure and sustainable energy systems incorporating solar and wind energy sources. 